\title{
Case Study: The Determination of a Complex Multi-Systemic Medical Condition by a Cognitive, Virtual Scanning Technique
}

\author{
Graham Wilfred Ewing \\ Mimex Montague Healthcare Limited, Nottingham, UK \\ Email: graham.ewing@mmhcl.co.uk
}

Received 27 April 2015; accepted 1 June 2015; published 4 June 2015

Copyright (C) 2015 by author and Scientific Research Publishing Inc.

This work is licensed under the Creative Commons Attribution International License (CC BY).

http://creativecommons.org/licenses/by/4.0/

(c) (i) Open Access

\section{Abstract}

The study of various medical conditions is limited by the current state of knowledge. New technologies enable researchers to advance their understanding of various medical conditions and to advance their understanding of particular pathologies. Strannik Virtual Scanning (SVS) is such a technology. SVS is able to determine the genetic and non-genetic components of every pathology in each of the $\mathbf{3 0}$ main organs, and it is able to determine the onset of pathologies at a much earlier stage than any other technologies or techniques. This makes it an ideal tool to screen for the onset and progression of pathologies which are implicated in multi-systemic conditions and to determine the spectrum of pathologies i.e. comorbidities which are involved in diabetes, cardiovascular disease, migraine, chronic fatigue syndrome, fibromyalgia, depression, chronic kidney disease, etc. This case study illustrates how the technology can be usefully and cost-effectively deployed to determine the spectrum of pathologies which characterise Reynaud's phenomenon. This includes pathologies in the liver and kidneys e.g. portal hypertension, renal insufficiency, nephritis, liver insufficiency, pre-symptomatic onset of heart attack, presymptomatic indications of dementia, pancreatic cancer, and ovarian cancer, which are difficult to diagnose and/or for which there is currently an unmet clinical need.

\section{Keywords}

Raynaud, Strannik, Strannik Virtual Scanning, Autonomic Dysfunction 


\section{Introduction}

Reynaud's phenomenon [1] [2] is a problem of blood supply to the extremities. The origins of RP have not been clearly identified. In some cases, it is due to emotional stress and it is often associated with smoking cigarettes; however, in common with many common morbidities, it must have neural, autonomic (ANS), and/or multi-systemic origins. It is considered to be a problem of the ANS, in particular the sympathetic nervous system, which causes vasoconstriction of the peripheral blood vessels which often leads to hypoxia in which regions of the body are deprived of an adequate supply of oxygen. It affects the connective tissues, the thickness and colour of the skin which may turn white or in extreme cases blue, and the temperature of the extremities [3] [4].

The pathological indications which accompany Raynaud's phenomenon include connective tissue disorders e.g. scleroderma, ulcerative processes, raised or lowered (idiopathic) blood pressure and/or cardiovascular disease(s) e.g. atherosclerosis, problems of the peripheral nervous system and hence loss of feelings in the extremities, rheumatoid arthritis, etc.

There is not currently a single rapid test which can be used to diagnose the onset and/or progression [5] of Raynaud's phenomena because the condition is a complex multi-systemic condition.

Secondary Raynaud's phenomenon often leads to sores or gangrene (tissue death) in the fingers and toes which can be painful and difficult to treat. In severe cases, there may be a requirement to treat skin ulcers and serious tissue damage, and/or for surgery including amputation.

\section{Diagnosis}

The current mechanism for diagnosis of Raynaud's phenomenon involves a complex set of diagnostic tests and criteria. This is summarised by [6] Maverakis, Patel and Kronenberg. Individual tests which are involved in making a diagnosis include:

- Digital artery pressure: by measuring the blood pressure in the arteries of the fingers before and after the hands have been cooled. A decrease of $\geq 15 \mathrm{mmHg}$ is considered to be confirmation of the condition.

- Ultrasound: to assess blood flow.

- Blood count: to assess whether anaemia or kidney disease may be a problem.

- Blood test of urea and/or electrolytes to assess whether kidney dysfunction is an issue.

- Thyroid tests.

- Antibody screen looking for signs of rheumatoid arthritis or inflammatory response (via erythrocyte sedimentation rate and/or C-reactive protein).

\section{Results Obtained Using Strannik Virtual Scanning}

SVS is based upon the observation that changes of colour perception have pathological origins and hence that measurements of colour perception could be related to a spectrum of pathological indications. SVS has been used to diagnose a wide spectrum of almost every conceivable disorder or combination of pathologies including, but not limited to, diabetes, cardiovascular disease, migraine, chronic fatigue syndrome, fibromyalgia, depression, etc.

Intriguingly Maricq and Weinrich [7] reported in 1988 that colour charts could be used to assist the diagnosis of Raynaud's phenomenon.

In this particular case study the patient was tested using the normal SVS protocol. See Strannik Operating Manual [8]. The SVS test results indicated:

- Systemic level: that "the regulation of blood volume" was the most destabilised physiological system (Figure 1) and that a Pathological Functional System (PFS) involving the brain and adrenal glands had been established (Figure 1).

- Organs (Figure 1): Heart, adrenals, kidneys, blood, pituitary, thyroid and brain were identified as the most dysfunctional organs.

- Cells (Figure 2): absence of processes associated with abnormal cell division.

- Psycho-oncological risk of onset is associated with duodenum, ovaries, ears, nose, oesophagus, and kidneys

- Molecular Level i.e. reported pathologies (Figures 3-13).

The most significant pathological indications reported are summarised as follows: 


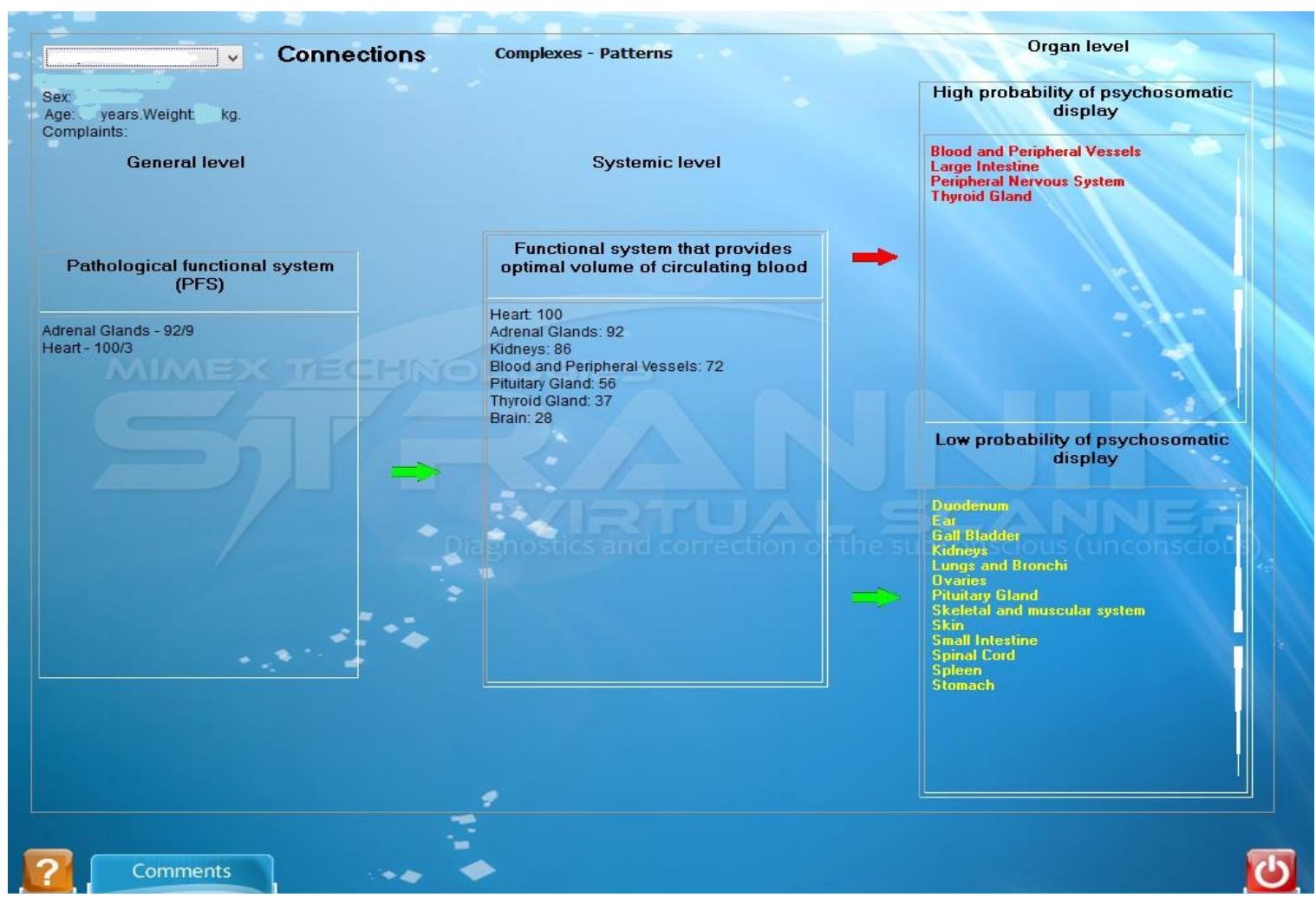

Figure 1. Systemic and organ stability.

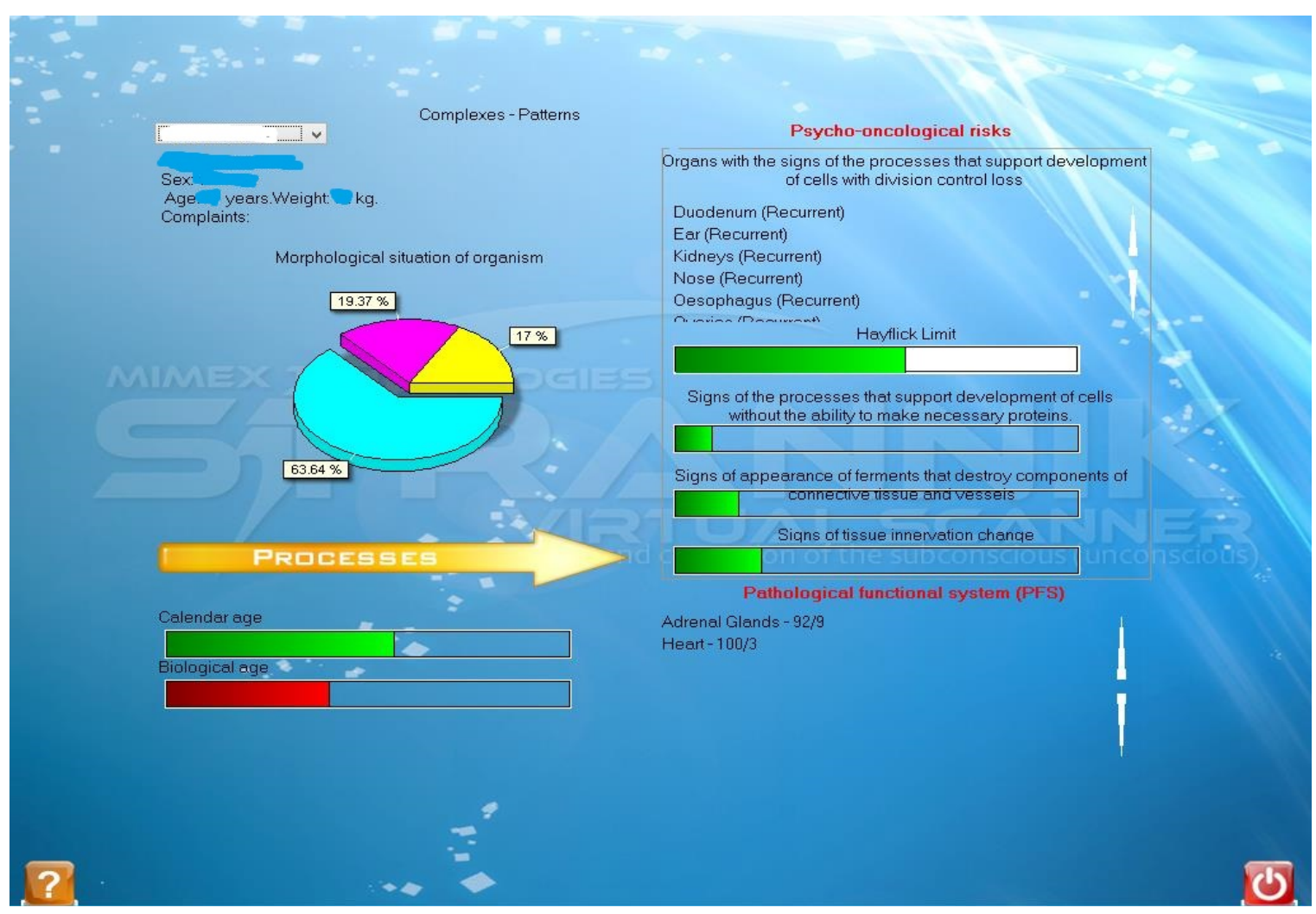

Figure 2. Prevailing morphology. 


\begin{tabular}{|c|c|c|c|}
\hline & Indication & Red/phenotype & Blue/Genotype \\
\hline \multirow[t]{2}{*}{ Brain } & Encephalopathy & 5 & 3 \\
\hline & Impaired cerebral circulation & 4 & 7 \\
\hline \multirow[t]{2}{*}{ Peripheral Nervous System } & $\underline{\text { Neuritis }}$ & 9 & 13 \\
\hline & Polyneuropathy & 2 & 18 \\
\hline Adrenal Gland & $\underline{\text { Adrenal Insufficiency }}$ & 27 & 7 \\
\hline Cushing Syndrome & 9 & 5 & \\
\hline \multirow[t]{2}{*}{ Liver } & Portal Hypertension & 5 & 7 \\
\hline & Liver Insufficiency & 7 & 4 \\
\hline \multirow[t]{3}{*}{ Pancreas } & Growth of New Cells & 5 & 28 \\
\hline & Diabetes (pre-onset type 1) & 1 & 9 \\
\hline & Pancreatitis & 6 & 9 \\
\hline \multirow[t]{2}{*}{ Heart } & Myocardial Dystrophy & 2 & 12 \\
\hline & Cardiac Insufficiency & 0 & 9 \\
\hline \multirow[t]{3}{*}{ Blood \& Peripheral Blood Vessels } & $\underline{\text { Anaemia }}$ & 4 & 15 \\
\hline & Phlebitis \& Thrombophlebitis & 7 & 3 \\
\hline & Idiopathic Hypotension & 7 & 1 \\
\hline Lungs \& Bronchii & Pneumonia & 6 & 6 \\
\hline \multirow[t]{2}{*}{ Oesophagus } & Growth of New Cells & 7 & 14 \\
\hline & Oesophagitis & 1 & 12 \\
\hline Duodenum & Duodenal Ulcer & 20 & 28 \\
\hline \multirow[t]{2}{*}{ Large Intestine } & Proctitis & 9 & 7 \\
\hline & Colitis & 5 & 4 \\
\hline \multirow[t]{4}{*}{ Kidneys } & Renovascular Insufficiency & 6 & 2 \\
\hline & Growth of New Cells & 8 & 4 \\
\hline & Glomerulonephritis & 3 & 18 \\
\hline & Urolithiasis & 1 & 14 \\
\hline \multirow[t]{3}{*}{ Skin } & Urticaria & 7 & 17 \\
\hline & Herpes & 12 & 2 \\
\hline & Psoriasis & 2 & 8 \\
\hline
\end{tabular}

Note 1: the genetic signals indicate the capacity of the organ to deal with a physiological event. In general they are indicative of a genetic pre-disposition and not an actual disposition i.e. it is only when the genetic condition is accompanied by a significant phenotypic indication, typically above 7 10 units, that this will be manifest as a pathological process and ultimately as "symptoms". 


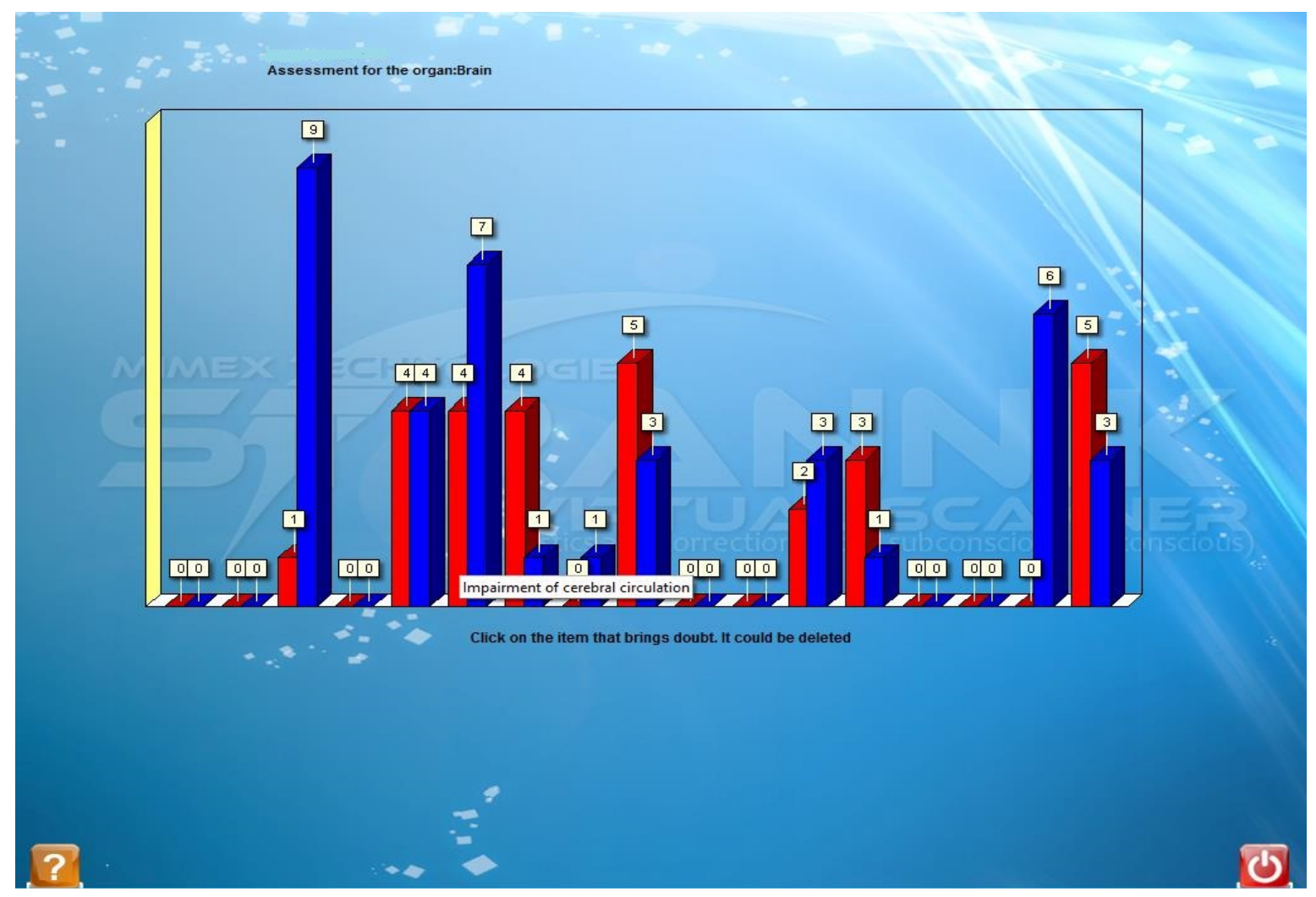

Figure 3. Pathologies reported in the brain.

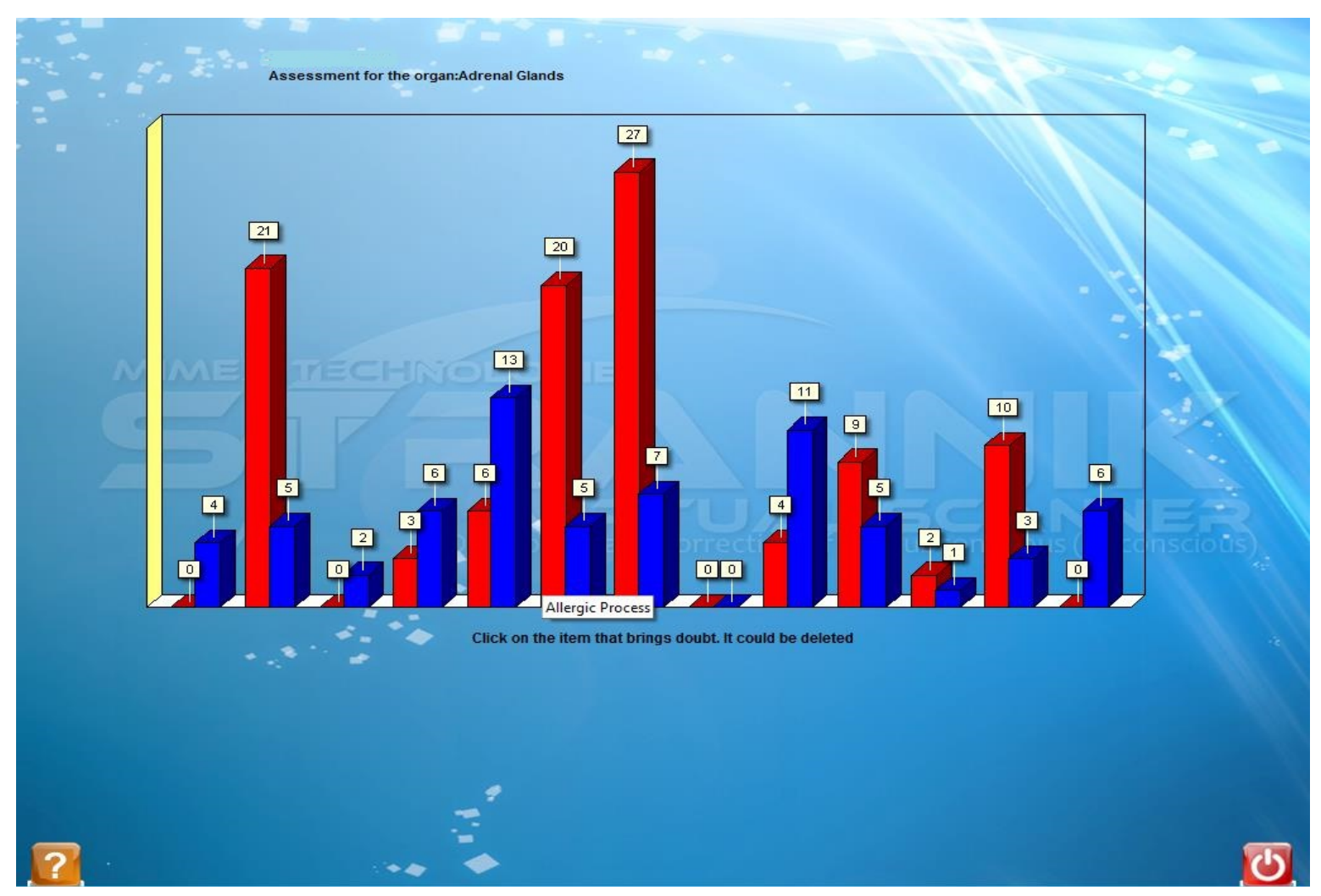

Figure 4. Pathologies reported in the adrenal glands. 


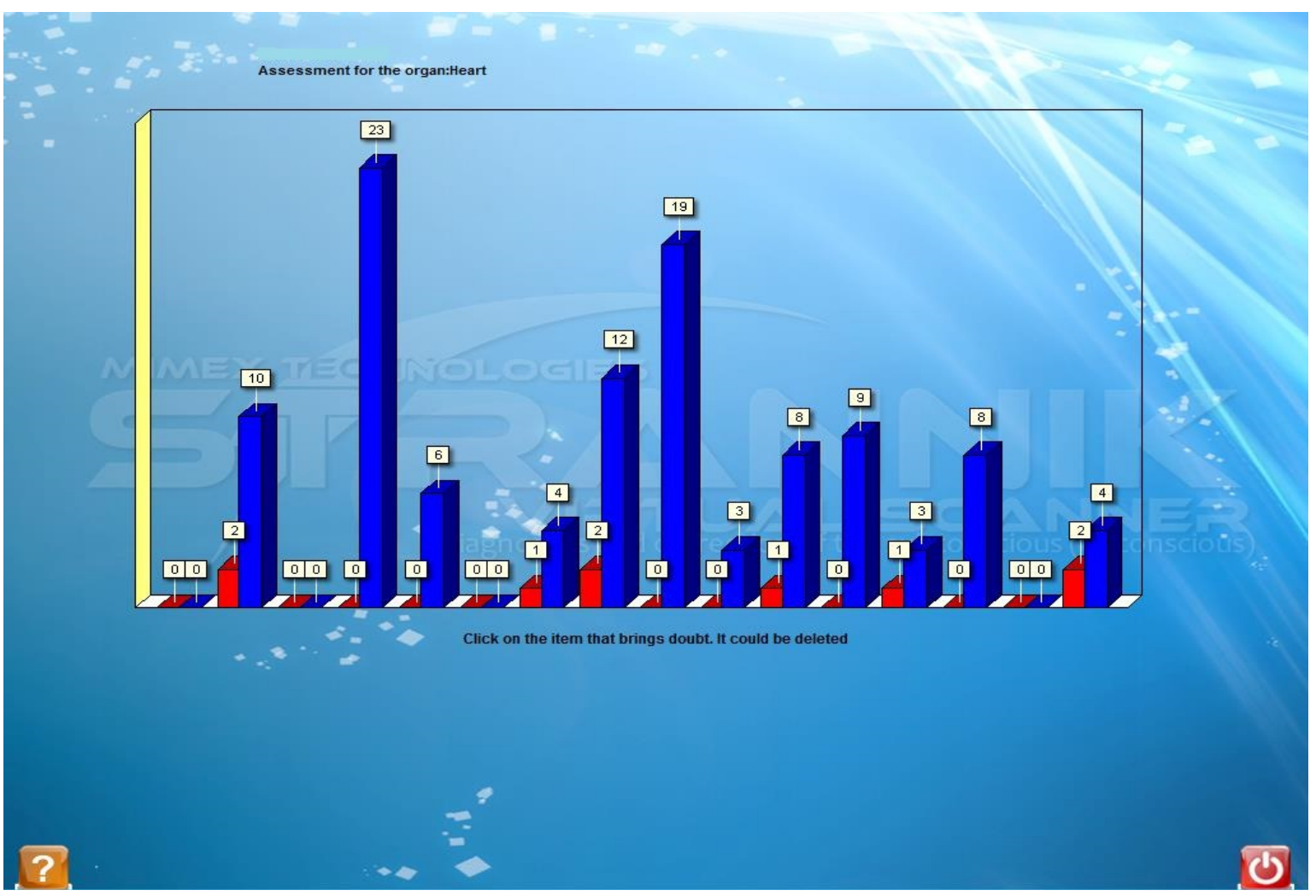

Figure 5. Pathologies reported in the heart.

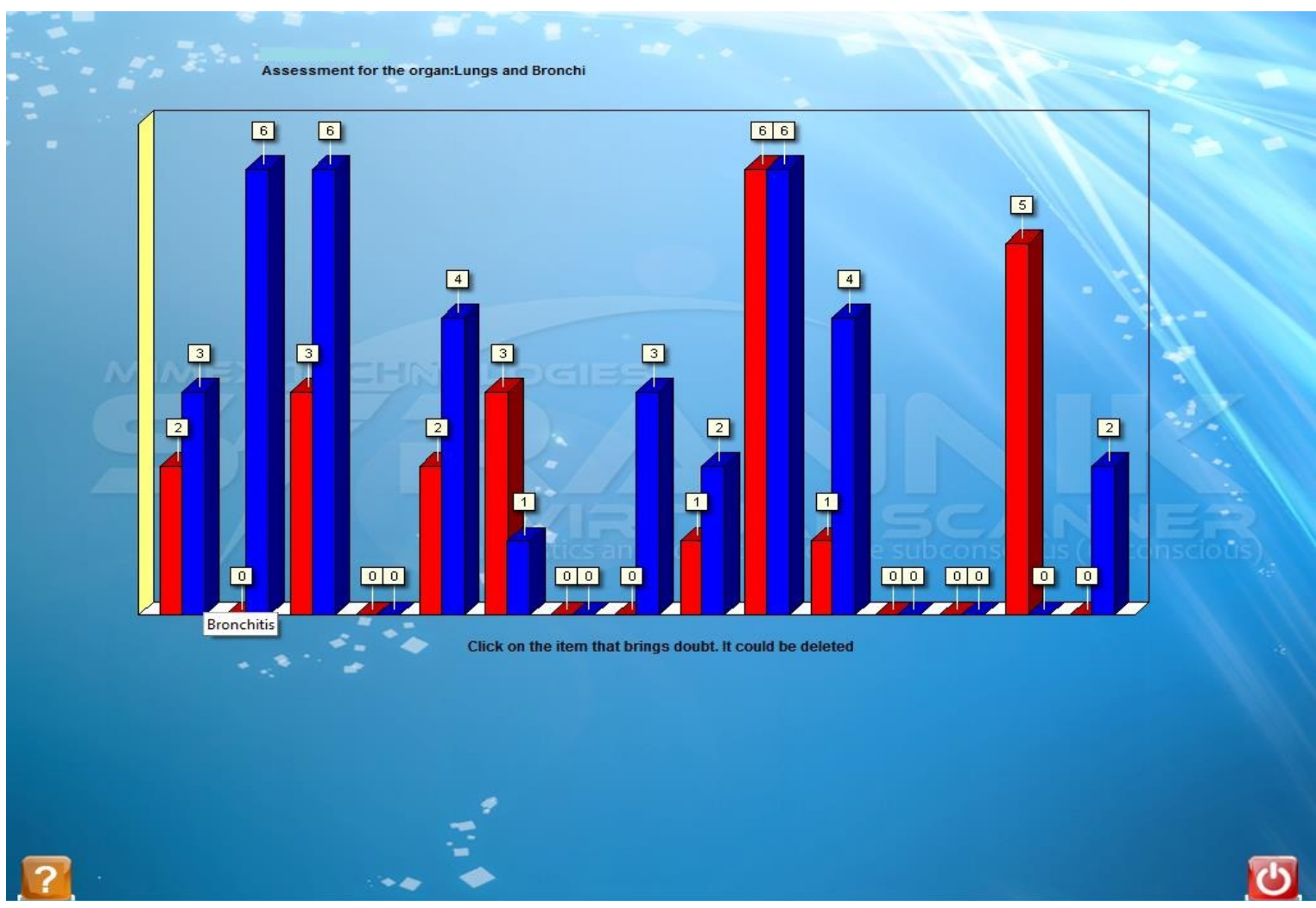

Figure 6. Pathologies reported in the lungs \& bronchii. 


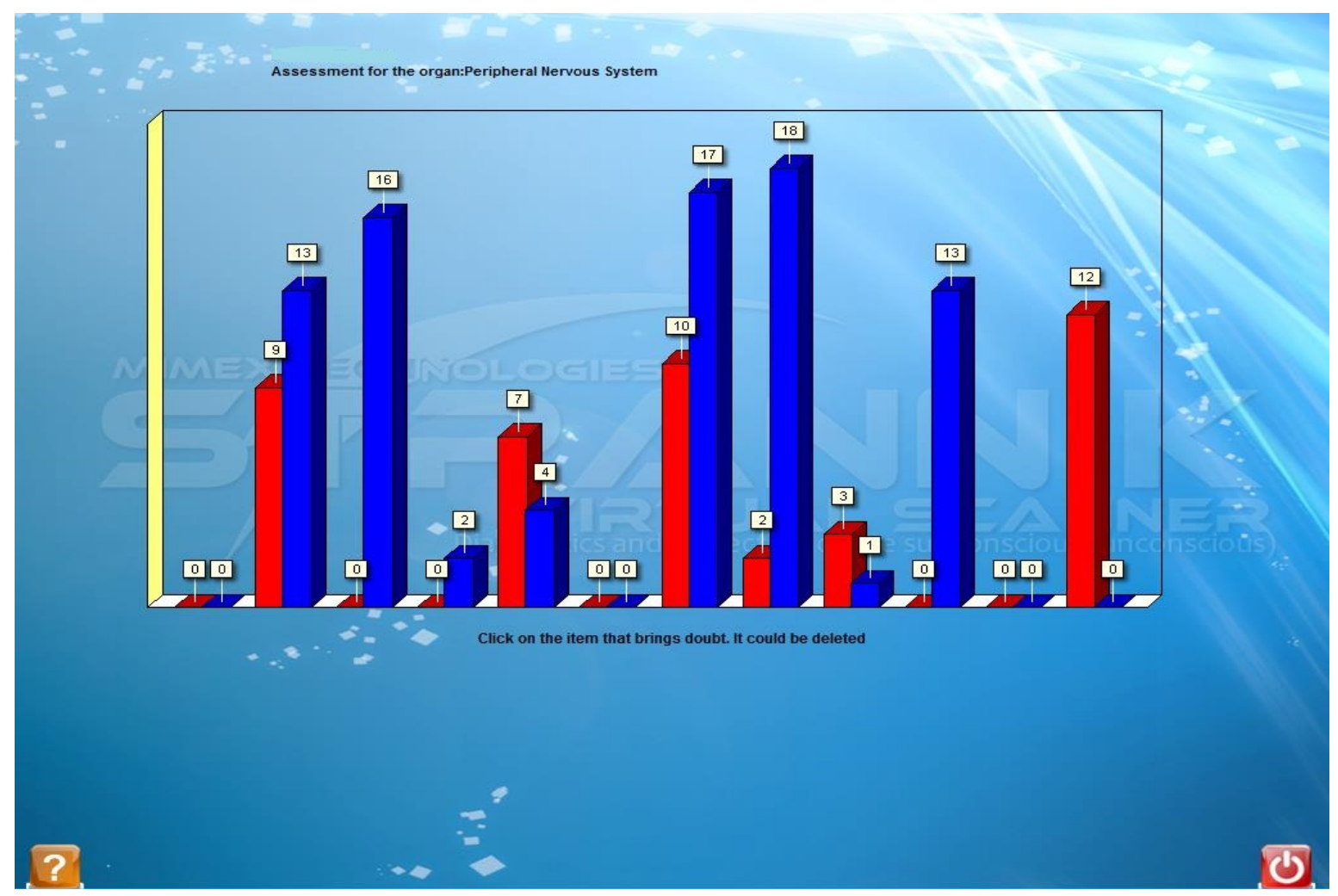

Figure 7. Pathologies reported in the peripheral nervous system.



Figure 8. Pathologies reported in the liver. 


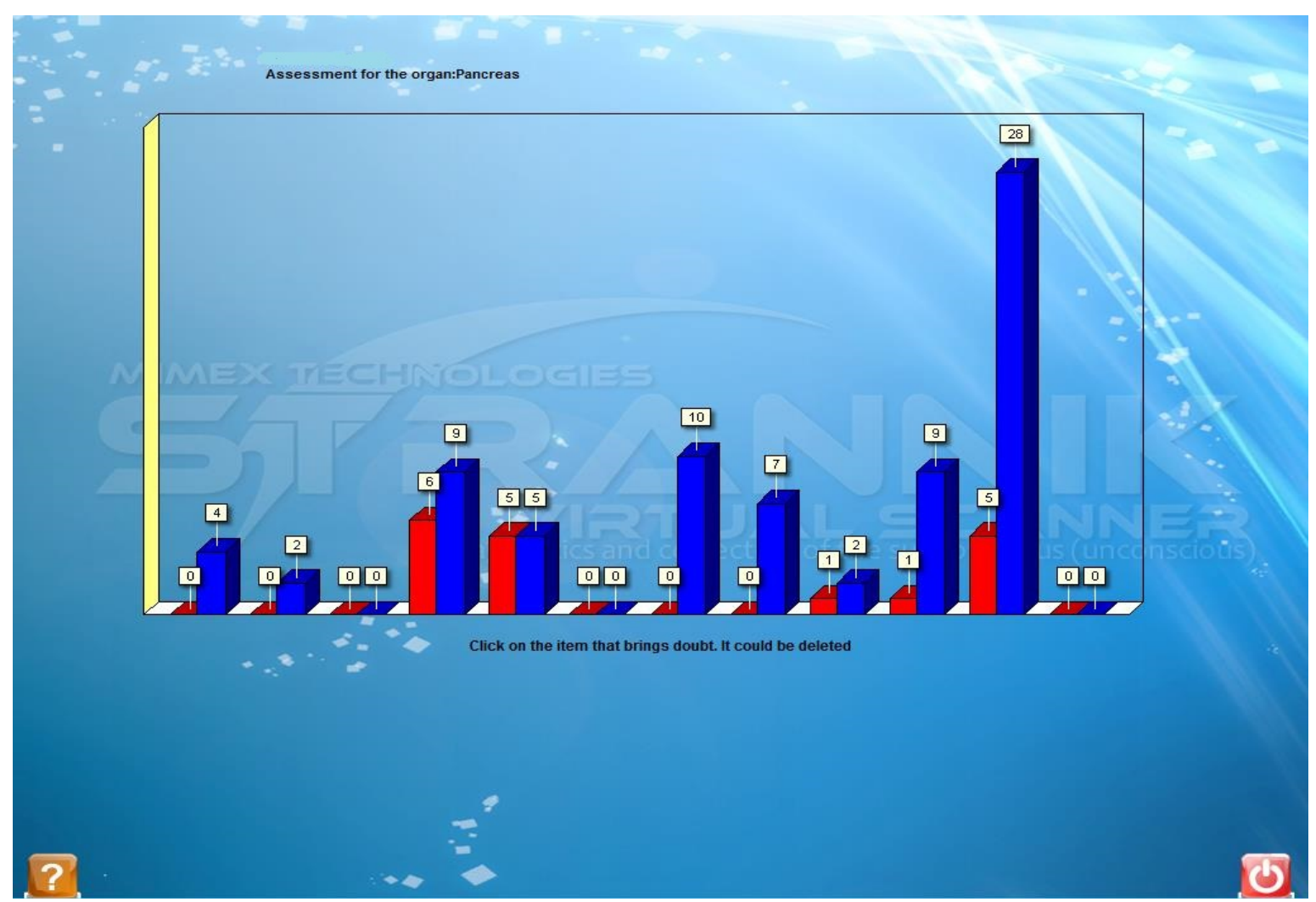

Figure 9. Pathologies reported in the pancreas.

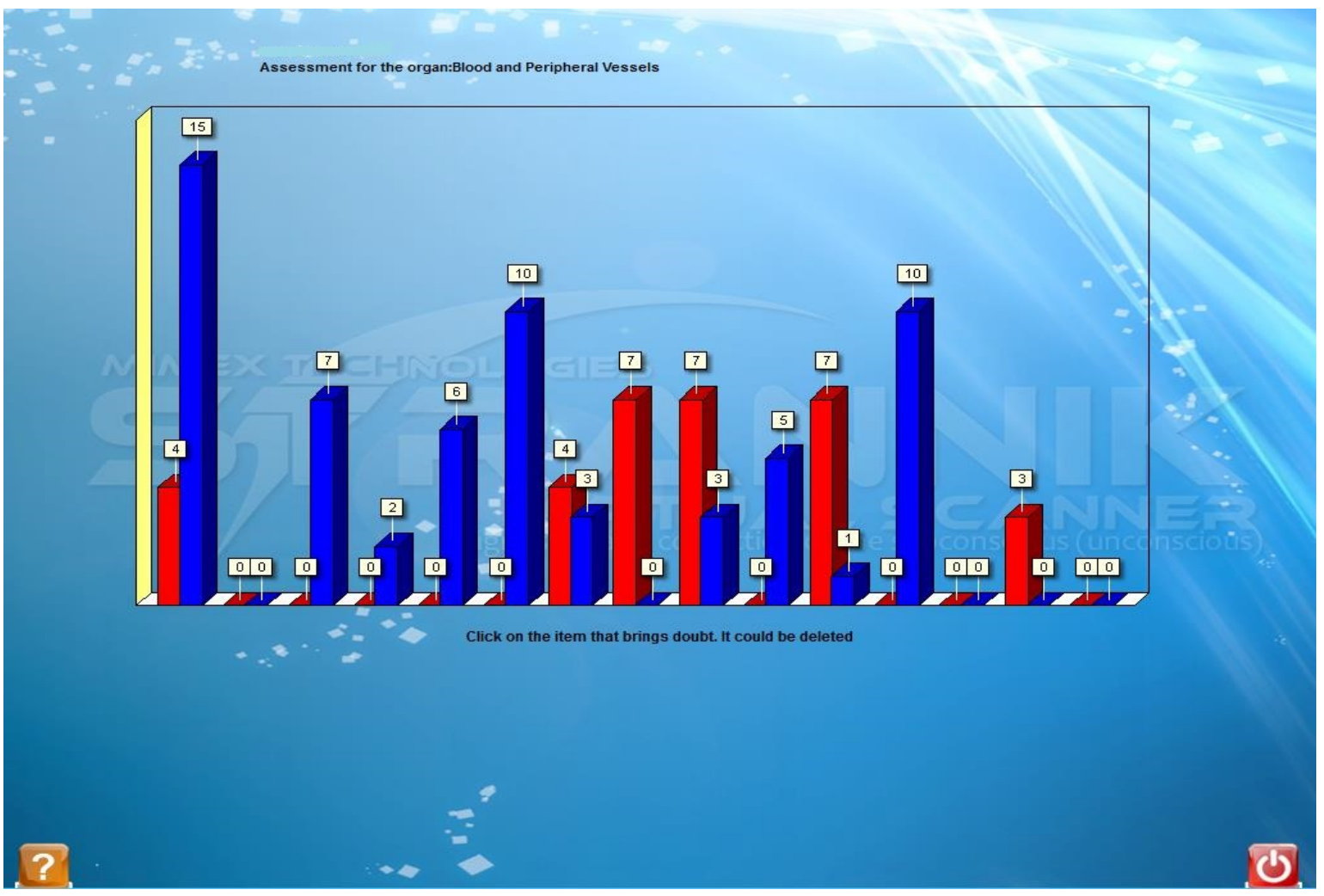

Figure 10. Pathologies reported in the blood \& peripheral blood vessels. 


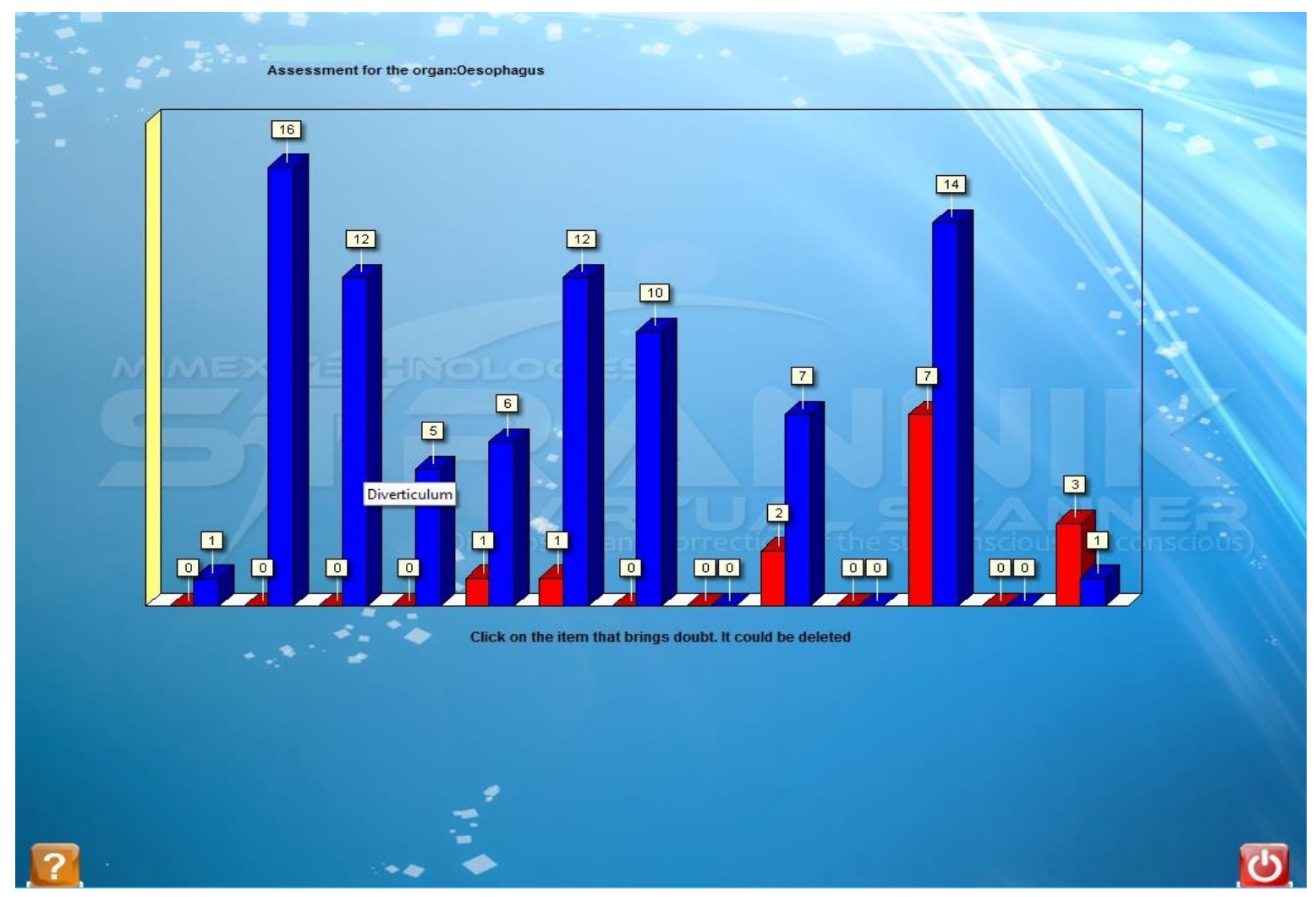

Figure 11. Pathologies reported in the oesophagus.

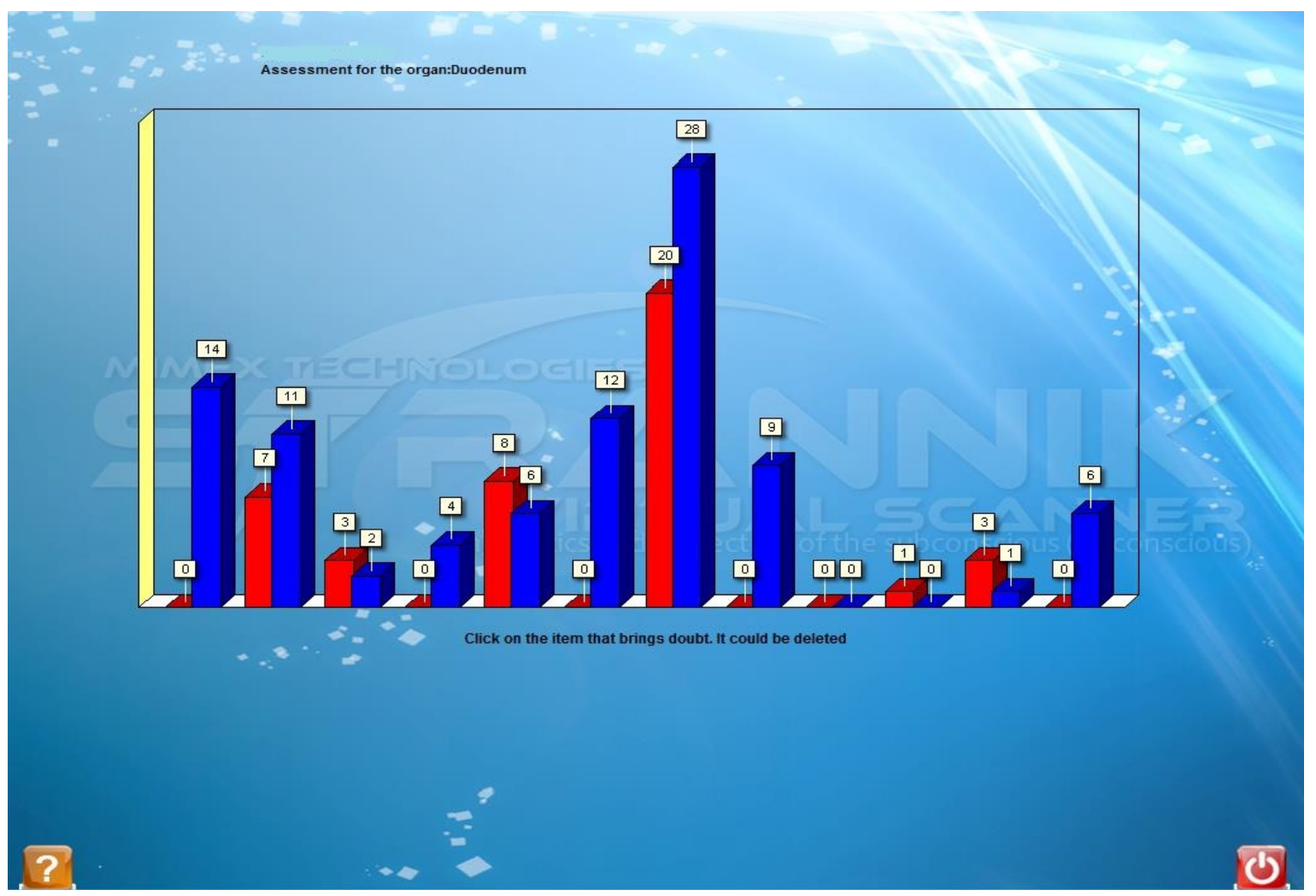

Figure 12. Pathologies reported in the duodenum. 


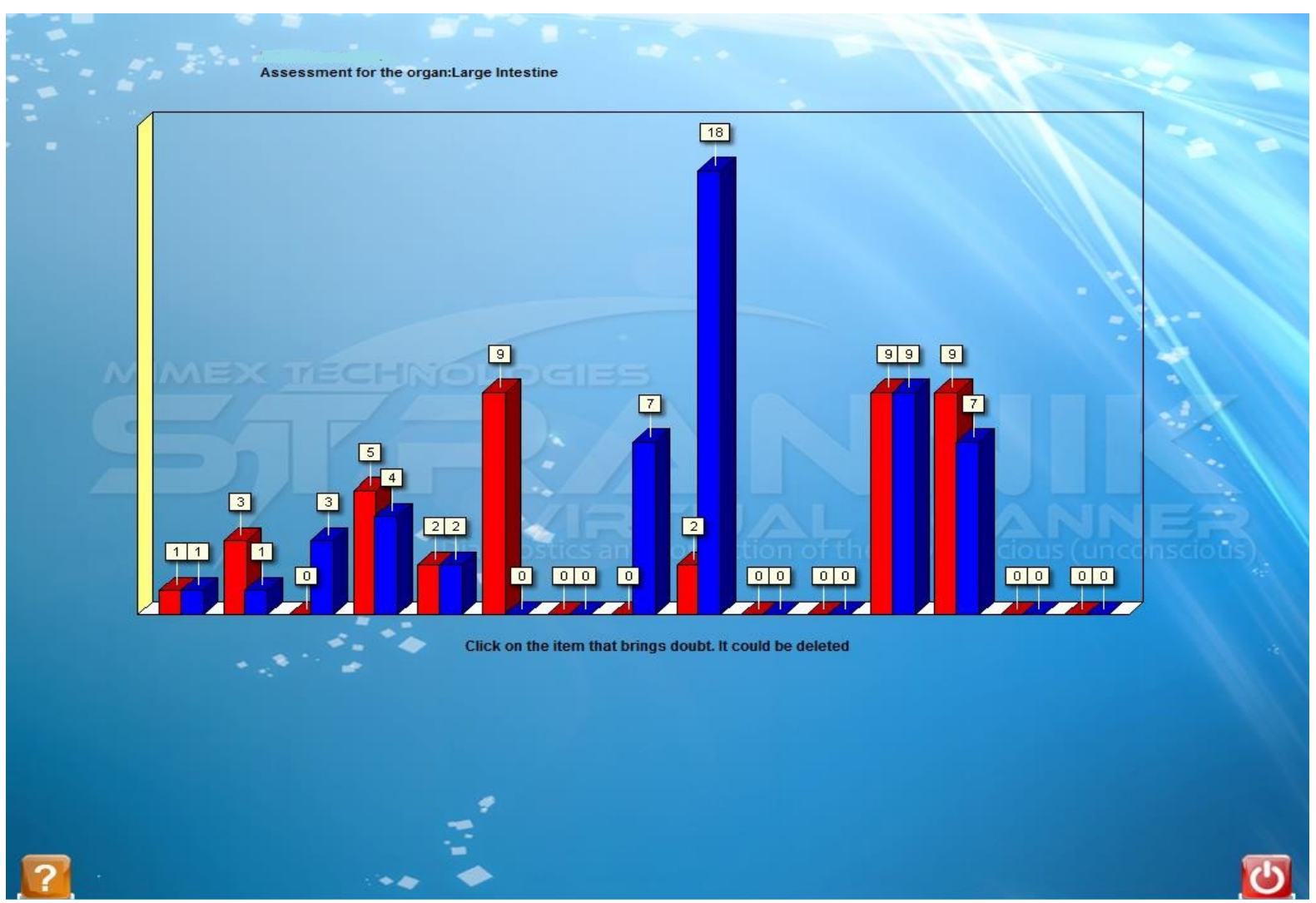

Figure 13. Pathologies reported in the large intestines.

Summary: the patient is suffering from extreme emotional stress. The consequences of this has resulted in impaired blood circulation throughout the vasculature and brain resulting in the earliest onset of portal hypertension, renal insufficiency, idiopathic hypotension, nephritis, adrenal insufficiency, anaemia, encephalopathy, neuritis, urticaria, and is showing earliest presymptomatic onset of type 1 diabetes. These are the "acute" conditions which are characteristic of the Raynaud's phenomenon.

In addition to the pathologies which are associated with the onset and progression of primary Raynaud's phenomenon the patient currently suffers from a duodenal ulcer andthere are indications that the patient has previously suffered a mild stress-related cardiovascular event/heart attack. These are the "chronic" conditions influencing this patient's health.

The patient would be expected to be suffering from problems with the heart, digestion of foods, stomach pains or aches, recurrent bouts of diarrhoeia, the general inability to function, a lack of mental clarity, pins and needles in the arms and legs, cold extremities, susceptibility to infections in particular of the lungs and brochii, lack of energy and impaired ability to function.

\section{The Patient's Reported Symptoms}

The patient reported that they had been previously diagnosed with Raynaud's phenomenon and that this was manifest as cold fingers and toes, "pins and needles", and a range of recurrent medical indications. They were interested to see if SVS could determine the various pathological indications which characterised their condition. The main issues of concern to the patient was to understand the degree of dysfunction influencing the patient's heart, lungs, peripheral nervous system, digestive system, and skin.

\section{Comparison of the Patient's Known Medical Condition with the SVS Health Report}

1) The particular medical indications reported by SVS were consistent with the patient's known medical his- 
tory, their personal concerns regarding their health, and the known etiology of Raynaud's phenomenon.

2) The fundamental problem is associated with impaired blood flow to the vasculature.

3) The pathological indications are consistent with long-term exposure to stress.

\section{Cost Implications}

An SVS test, when taking into account the overheads of operation, cost of employing someone to administer the test, etc; is estimated at $£ 50-100 /$ test. By comparison a diagnosis of Raynaud's disease would involve at least one consultation with the patient's GP and several consultations with doctors and/or consultants in secondary care. It would also require long-term treatment by drugs.

It is considered to be an ideal condition for which SVS could be used to determine the onset and progression of the various Raynaud's pathologies and for treatment by Strannik Light Therapy.

Estimated SVS Cost based upon having two GP consultations pa: $£ 100$ - 200.

\subsection{Primary Raynaud's Phenomenon}

The tests used to characterise the RP patient's condition include:

Digital artery pressure

Blood test

Nail Fold Vasculature

Estimated costs:

\section{Ultrasound}

Thyroid function test

$£ 250$ - 500 pa.

\section{On-Going Drug Use}

There is not a recognised way of alleviating the onset and progression of RP. The normal line of treatments for moderate or severe RP are dependent upon the symptoms to be treated:

- Vasodilators [9] [10]: typically the calcium channel blockers nifedipine and/or diltiazem.

- Blood thinning medications: patients with severe RP prone to ulceration or thrombotic events may be prescribed aspirin or ACE-inhibitors to aid blood flow to the fingers. There is some evidence that angiotensin receptor blockers (e.g. losartan) reduce the frequency and severity of attacks.

- Sympatholytic agents:which inhibits the functioning of the SNS e.g. the prazosin [11]. They are indicated for various functions, for example as antihypertensives and/or to treat anxiety, Panic Disorder and PTSD.

- Medications which raise blood pressure [12] [13]: e.g. losartan, may reduce the severity and frequency of attacks, whilst phosphodiesterase inhibitors may reduce their severity.

- Medications which lower blood pressure e.g. i) the prostaglandin iloprost is used to manage critical ischemia and pulmonary hypertension in RP, whilst ii) endothelin receptor antagonists e.g. bosentan, may be used to manage severe cases of pulmonary hypotension and prevent finger ulcers.

Estimated annual cost ranging upon the severity of the condition, the extent of medical consultations e.g. in primary or secondary care, and the drugs used to treat the various symptoms: £250 - 2500 pa.

\subsection{Secondary Raynaud's Phenomenon}

The progression of Raynaud's phenomenon may lead to surgical procedures involving cutting the nerves that constrict the flow of blow to the fingertips, removal of toes, fingers, etc [14].

Estimated Cost of Amputation: £5 - $15 \mathrm{k}$.

\subsection{Cost of Treating Raynaud's Phenomenon throughout the Patient's Life}

It is not possible to make a precise prediction or estimate of the cost of diagnosing/monitoring, and treating the health of the Raynaud's patient. The onset of the condition will be dependent upon the nature of the factors which are causing this condition and the patient's ability to deal with the problem. Nevertheless it is clear that the complexity and cost of healthcare, provided by the GP [15], to the Raynaud's patient will rise steadily during the course of this condition from its earliest pre-diagnosis which would incur costs of typically $£ 100$ - $250 \mathrm{pa}$, to the primary phase which could reasonably be expected to incur costs of typically $£ 250-2500 \mathrm{pa}$, and the secondary phase which will require intensive drug-use, surgical procedures, hospitalisation and intensive nursing support at an estimated annual cost of $£ 5000$ and perhaps significantly more. By comparison an SVS test, if de- 
ployed as a screening tool, is able to track the onset and progression of Raynaud's phenomenon for an estimated $£ 100$ - 200 pa.

Finally, as the condition may have stress-related origins, it may be useful to consider stress-relieving strategies as the first line of treatment of Raynaud's patients.

\section{Conclusions}

It is a particular failing of modern medicine that it is poorly able to characterise and diagnose many of the common lifestyle-related morbidities [16]. The emphasis upon single biochemical determinants (biomarkers) ignores the complex multi-systemic way in which the brain regulates the autonomic nervous system and physiological systems, and the even more complex range of pathological consequences which arise from autonomic dysfunction. Furthermore, the emphasis upon having an individual test for each presenting co-morbidity merely adds to the complexity and cost of healthcare. There is therefore a need throughout medicine, not just regarding the diagnosis of Raynaud's phenomenon, for a screening technology which can comprehensively and inexpensively determine and monitor the co-morbidities which present in such cases AND to better understand how the autonomic nervous system functions in order to treat the vast plethora of medical conditions which arise as a result of the autonomic dysfunction which arises from the effect of various stressors.

Strannik technology is the first technology to be based upon a mathematical model of the autonomic nervous system. This article highlights the potential of Strannik Virtual Scanning to simplify the task of monitoring the health of an RP patient and also to significantly reduce the cost of doing so throughout the RP patient's life.

According to the National Health Service in the UK [17] as many as 1 in 6 of the population-an estimated 10 million of the UK population-may suffer from some degree of RP during their lives. The condition may be acute e.g. accompanying childbirth or during periods when the patient smoked cigarettes, or it may be chronic.

Accordingly this article illustrates how the cost of diagnosing the onset and progression of co-morbidities in the RP patient, and perhaps also the cost of treating RP, can be significantly reduced by using Strannik Virtual Scanning \& Strannik Light Therapy [8].

\section{Acknowledgements}

The author thanks Dr Elena Ewing MD for her assistance.

\section{References}

[1] Saigal, R., Kansal, A., Mittal, M., Singh, Y. and Ram, H. (2010) Raynaud’s Phenomenon. JAPI, 58, 309-313.

[2] Gallaraga, B.J. (2008) Raynaud’s Phenomenon. Synopsis of Causation. https://www.gov.uk/government/uploads/system/uploads/attachment_data/file/384542/raynauds_phenomenon.pdf

[3] Goundry, B., Bell, L., Langtree, M. and Moorthy, A. (2012) Diagnosis and Management of Raynaud's Phenomenon. British Medical Journal, 344, e289. http://dx.doi.org/10.1136/bmj.e289

[4] Brown, S. (2012) Diagnosis and Management of Patients with Raynaud's Phenomenon. Nursing Standard, 26, 41-46. http://dx.doi.org/10.1002/art.21912

[5] Hirschl, M., Hirschl, K., Lenz, M., Katzenschlager, R., Hutter, H.-P. and Kundi, M. (2006) Transition from Primary Raynaud's Phenomenon to Secondary Raynaud's Phenomenon Identified by Diagnosis of an Associated Disease. Arthritis \& Rheumatism, 54, 1974-1981. http://dx.doi.org/10.1002/art.21912

[6] Maverakis, E., Patel, F. and Kronenberg, D. (2014) International Consensus Criteria for the Diagnosis of Raynaud's Phenomenon. Journal of Autoimmunity, 48-49, 60-65. http://dx.doi.org/10.1016/j.jaut.2014.01.020

[7] Maricq, H.R. and Weinrich, M.C. (1988) Diagnosis of Raynaud's Phenomenon Assisted by Color Charts. Journal of Rheumatology, 15, 454-459.

[8] www.montaguehealthcare.co.uk/OperatingManual.pdf

[9] Kahan, A., Weber, S., Amor, B., Saporta, L., Hodara, M. and Degeorges, M. (1981) Nifedipine and Raynaud's Phenomenon. Annals of Internal Medicine, 94, 546. http://dx.doi.org/10.7326/0003-4819-94-4-546_1

[10] Ennis, H., Anderson, M.E., Wilkinson, J. and Herrick, A.L. (2014) Calcium Channel Blockers for Primary Raynaud's Phenomenon. Cochrane Database of Systematic Reviews, 1, CD002069. http://dx.doi.org/10.1002/14651858.cd002069.pub4

[11] Waldo, R. (1979) Prazosin Relieves Raynaud's Vasospasm. JAMA, 241, 1037. http://dx.doi.org/10.1001/jama.1979.03290360053028 
[12] Pancera, P., Sansone, S., Secchi, S., Covi, G. and Lechi, A. (1997) The Effects of Thromboxane A2 Inhibition (Picotamide) and Angiotensin II Receptor Blockade (Losartan) in Primary Raynaud's Phenomenon. Journal of Internal Medicine, 242, 373-376. http://dx.doi.org/10.1046/j.1365-2796.1997.00219.x

[13] Dziadzio, M., Denton, C.P., Smith, R., et al. (1999) Losartan Therapy for Raynaud's Phenomenon and Scleroderma: Clinical and Biochemical Findings in a Fifteen-Week, Randomized, Parallel-Group, Controlled Trial. Arthritis and Rheumatism, 42, 2646-2655. http://dx.doi.org/10.1002/1529-0131(199912)42:12<2646::AID-ANR21>3.0.CO;2-T

[14] http://health.costhelper.com/amputation.html

[15] (2014) RCGP Curriculum 2010. Statement 2.01. The GP Consultation in Practice. http://www.gmc-uk.org/2_01_The_GP_consultation_in_practice_May_2014.pdf_56884483.pdf

[16] Ewing, G.W. (2013) A Comparison of the Diagnostic Scope of Biomarker Techniques, Genetic Screening and Virtual Scanning. Immunology, Endocrine \& Metabolic Agents in Medicinal Chemistry, 13, 35-45. http://dx.doi.org/10.2174/1871522211313010004

[17] http://www.nhs.uk/Conditions/Raynauds-phenomenon/Pages/Introduction.aspx

\section{Abbreviations}

SVS: Strannik Virtual Scanning

ANS: Autonomic Nervous System

RP: Raynaud's Phenomenon

SLT: Strannik Light Therapy 